\title{
Synthesis of zinc oxide and silver nanoparticles using ficus palmata - Forssk leaf extracts and assessment of antibacterial activity
}

\author{
Sabaoon Shamshad ${ }^{1^{*}}$, Jamshaid Rashid ${ }^{1,2,3^{\dagger *}}$, Ihsan-ul-haq ${ }^{4}$, Naseem Iqbal ${ }^{5}$, Saif Ullah Awan ${ }^{6^{*}}$ \\ ${ }^{1}$ Department of Environmental Science, Faculty of Biological Sciences, Quaid-i-Azam University, Islamabad 45320, Pakistan \\ ${ }^{2}$ College of Environment and Planning, Henan University, Kaifeng 475004, China \\ ${ }^{3}$ Key Laboratory of Ceospatial Technology for the Middle and Lower Yellow River Regions (Henan University), Ministry of Education, Kaifeng \\ 475004, China \\ ${ }^{4}$ Department of Pharmacy, Quaid-i-Azam University, Islamabad 45320, Pakistan \\ ${ }^{5}$ US-Pakistan Centre for Advanced Studies in Energy (USPCAS-E), National University of Sciences and Technology, Islamabad, Pakistan \\ ${ }^{6}$ Department of Electrical Engineering, NUST College of Electrical and Mechanical Engineering, National University of Science and Technology (NUST), \\ Islamabad 54000, Pakistan \\ "These authors contributed equally to this work
}

\begin{abstract}
Multidrug resistance of bacteria is an emerging human health hazard and warrants development of novel antibacterial agents with more effective mode of action. Here, zinc oxide and silver nanomaterials were prepared using Ficus palmata Forssk leaf extract with efficient antibacterial activity. SEM coupled with EDS confirmed the spherical symmetry with average particle diameter 50 to $65 \mathrm{~nm}$ while the XRD confirmed crystalline face centered cubic structure of silver and hexagonal crystallize phase of zinc oxide nanoparticles. Antibacterial activity was evaluated for 8 pathogenic bacterial strains including 3 drug resistant pathogenic strains. The nanoparticles showed enhanced growth inhibition for resistant strains in comparison with the broad-spectrum antibiotics i.e. roxithromycin and cefixime. Minimum inhibitory concentration in $\mu \mathrm{g} . \mathrm{mL}^{-1}$ of silver nanoparticles was found to be as low as 33.3 for resistant Streptococcus haemolyticus; 11.1 for Staphylococcus aureus and E Coli; and $3.7 \mu$ g.mL ${ }^{-1}$ for resistant Pseudomonas aeruginosa. Similarly, the minimum inhibitory concentration of zinc oxide nanoparticles was found to be $100 \mu \mathrm{g} . \mathrm{mL}^{-1}$ against resistant Streptococcus haemolyticus and Staphylococcus aureus; $11.1 \mu \mathrm{g} \cdot \mathrm{mL}^{-1}$ for resistant Pseudomonas aeruginosa; and $3.7 \mu \mathrm{g} . \mathrm{mL}^{-1}$ against resistant $E$ coli. Ficus palmata Forssk leaf extracts can be explored effectively for synthesizing active antibacterial nanomaterials as a non-toxic and environmentally benign synthesis route.
\end{abstract}

Keywords: Antibacterial activity, Biosynthesis, Ficus palmate, Growth inhibition, Silver nanoparticles, Zinc oxide nanoparticles

\section{Introduction}

Pharmaceuticals, surfactants, disinfection by-products, personal care products, pesticides and plasticizers are among chemical compounds of daily use which upon entering into the environment are considered as emerging contaminants (EC) [1]. These pharmaceutical compounds are potential contaminants for human health as well as the environment due to their extensive utilization and persistence. Antibiotics constitute major proportion of the pharma- ceutical compounds for human medicine, aquaculture, animal husbandry, veterinary and agriculture [2]. These antibiotics are thus found in all environmental media due to excessive production, utilization and unsafe disposal. The presence of such antibiotics in environment has led to an increase in antibiotic resistance in microbes which is of great concern nowadays. Release of pathogenic bacteria through wastewater addition into the aquatic environments has increased concerns over the ecological impacts of antibiotics [3]. Bacteria that used to be sensitive to antibiotics have now become
This is an Open Access article distributed under the terms of the Creative Commons Attribution Non-Commercial License (http://creativecommons.org/licenses/by-nc/3.0/) which permits unrestricted non-commercial use, distribution, and reproduction in any medium, provided the original work is properly cited.

Copyright (C) 2021 Korean Society of Environmental Engineers
Received August 11, 2020 Accepted October 20, 2020

${ }^{\dagger}$ Corresponding author

Email: jamshaidrashid@gmail.com

Tel: +925190644138 Fax: +925190644110

ORCID: 0000-0001-8031-121X 
resistant to a variety of antibacterial agents, mandating improvements in existing disinfection technologies [4, 5]. Recently researchers are trying to develop nanotechnology based water treatment and management systems in search of more efficient and cost effective treatment options against drug resistant pathogens $[6,7]$. Enhanced beneficial attributes of nano-sized particles are owed to their surface to volume ratio, structure and morphological features compared to parent materials [8]. The metallic nanomaterials in this scenario have shown notable antibacterial efficiency because of the huge surface areas [9]. The antibacterial activity of nanoparticles has created new application as novel antimicrobial agents that target cell membrane of the resistant microbe in a different manner [10, 11].

Numerous synthesis routes for nanomaterials have been reported by researchers such as solvothermal, sono-chemical, and reverse micro-emulsion showing excellent antimicrobial activity, however, the solvents and other precursors required for in such synthesis routes are unfortunately highly toxic [12]. In order to develop biodegradable and biocompatible nanoparticles a rapid shift has been observed in nanoparticle synthesis strategies from physico-chemical to biological techniques [13, 14] which involve the use of bio-resources like fungi, bacteria and plants for nanoparticles synthesis [15, 16]. Green synthesis for environmental and medical applications is a recently growing technology. It involves utilization of plant borne chemicals for synthesizing nanomaterials as a robust and environment friendly method without high pressure, energy or temperature requirements [17]. In these methods natural reducing agents replace the hazardous or flammable chemical solvents otherwise used in wet chemical synthesis routes to produce metal nanoparticles. Medicinal plants have been considered for producing large number of natural chemical agents that exhibit antioxidant activities. For instance, Ficus palmata leave extracts have been reported to contain alkaloids, tannins, flavonoids, terpenoids and cardiac glycosides [18]. Similarly, leaves of Ficus carica have been reported to possess reducing as well as capping agents that can reduce harmful $\mathrm{Ag}^{+}$ions in to $\mathrm{Ag}^{0}$ ions [19]. Nano-dimensional silver [20-27] and zinc oxide [28-32] prepared by green synthesis routes have been reported recently with high antibacterial, antifungal, antioxidant and anticancer activities [27-32].

The present work reports the use of Ficus palmate Forsk leaves extracts for the production of zinc oxide and silver nanoparticles as a green synthesis route to be utilized as a potent anti-bacterial remedy against pathogenic and resistant bacteria.

\section{Materials and Methods}

\subsection{Materials}

Silver nitrate $\left(\mathrm{AgNO}_{3}\right)$ and Zinc acetate dihydrate [Zn $\left(\mathrm{CH}_{3} \mathrm{COO}\right)_{2} \cdot 2 \mathrm{H}_{2} \mathrm{O}$ ] were used as precursors for silver and zinc oxide, respectively. Sodium hydroxide $(2 \mathrm{M} \mathrm{NAOH})$ solution in deionized water was used for $\mathrm{pH}$ adjustment. Plant extract was stored/ preserved at $4{ }^{\circ} \mathrm{C}$. The $\mathrm{pH}$ of the samples was determined by 8000 Adwa (Hungary Kft.) pH meter. Centrifugation was performed using Jouan centrifuge BR4i (DJB Labcare Ltd England). Memmert UN 55 (Germany) drying oven was used for drying of the nanomaterials. Nutrient agar plate (after the growth of bacterial colonies) incubated at $37^{\circ} \mathrm{C}$ (Isotemp Oven, Fisher Scientific, USA). Optical density $\left(\mathrm{OD}_{630}\right)$ of the bacterial inoculums was measured by microplate reader ELx800 (Cole-Parmer, Canada) at $630 \mathrm{~nm}$.

\subsection{Test Organisms}

Staphylococcus aureus (ATCC-6538), Bacillus subtilis (ATCC-6633), Klebsiella pneumoniae (ATCC-1705), Pseudomonas aeruginosa (ATCC-15442), Escherichia coli (ATCC-25922), Resistant Pseudomonas aeruginosa (MIC-103), Resistant E. coli (MIC-102) and Resistant Streptococcus haemolyticus (MIC-101) (hereafter represented as $S A, B S, K P, P A, E C, R P A, R E C$ and $R S H$, respectively), were provided by Department of Microbiology, Shah Abdul Latif University, Khairpur, Pakistan.

\subsection{Synthesis of Silver and Zinc Oxide Nanoparticles}

\subsubsection{Preparation of plant extract}

Ficus palmata leaves were plucked from the trees growing in the gardens of Quaid-i-Azam University and were immediately brought to the Catalysis for Energy and Environment Laboratory, QAU, Pakistan for further processing. Plant leaves were first rinsed with tap water followed by distilled water washing. Leaves were then placed on newspaper and dried under direct sunlight. Dried leaves were then subjected to grounding to obtain fine powder. $10 \mathrm{gm}$ of fine leaf powder was added to $100 \mathrm{~mL}$ water followed by 15 min boiling with constant stirring at $500 \mathrm{rpm}$ using magnetic stirrer. The mixture thus obtained was then allowed to cool for some time, was filtered and stored at $4^{\circ} \mathrm{C}[10]$.

\subsubsection{Nanomaterial synthesis}

The zinc oxide and silver nanoparticles (ZnO NP and Ag NP, respectively) were prepared as previously reported with some modifi cations [9, 17]. Zinc accetate (6 g) was added to $60 \mathrm{~mL}$ water, $20 \mathrm{~mL}$ extract was first boiled for $10 \mathrm{~min}$ at $50^{\circ} \mathrm{C}$ and $\mathrm{Zn}$ $\left(\mathrm{CH}_{3} \mathrm{COO}\right)_{2} \cdot 2 \mathrm{H}_{2} \mathrm{O}$ solution was added drop wise. At that time the color of plant extract started fading and $\mathrm{pH}$ of the solution mixture was checked which was found to be slightly acidic. It was raised to 11.5 by adding $2 \mathrm{M} \mathrm{NaOH}$ solution. A complete color change was observed and cream-colored precipitate started forming which was the indication of formation of zinc hydroxide $\left(\mathrm{Zn}(\mathrm{OH})_{2}\right)$. After centrifugation at 7,000 rpm for $15 \mathrm{~min}$ the precipitates were washed, oven dried at $60^{\circ} \mathrm{C}$, subsequently ground and stored.

For Ag NP synthesis $10 \%(\mathrm{w} / \mathrm{v})$ of leaf extract was added to $6 \mathrm{mM} \mathrm{AgNO}$ 1:4 with constant stirring. Appearance of brown color was the indication of $\mathrm{Ag}^{+}$being reduced to $\mathrm{Ag}^{0}$ and thus Ag NP synthesis [10]. The mixture was then autoclaved (5 min (a) $121^{\circ} \mathrm{C}$ and $\left.15 \mathrm{psi}\right)$. Thereafter, the mixture was dispersed in distilled water and centrifuged for purification; dried at $80^{\circ} \mathrm{C}$ and was stored at room temperature for further use.

\subsection{Characterization}

The morphology and elemental mapping of nanomaterials were determined by using SEM fitted with EDAX using Hitachi S-4800 microscope operated at $20 \mathrm{kV}$. Prepared nanoparticles were subjected to XRD analysis for determining the crystalline structure with D8, BRUKER AXS diffractometer using $\mathrm{Cu} \mathrm{K}_{\alpha}$ radiation ( $\alpha$ $=0.15425 \mathrm{~nm})$. 


\subsection{Antibacterial Activity}

The synthesized nanoparticles were tested against 8 different bacterial strains. For these studies, two broad spectrum antibiotics i.e., cefixime and roxithromycin were used as a control group. All the materials and equipment used for antibacterial screening assay were autoclaved. Overnight fresh bacterial cultures were used for the analysis. A suspension was prepared by diluting bacterial colonies in pre-autoclaved nutrient broth in ratio 1: 9. This inoculum was further used in the experiment. Minimum concentration of samples used for growth inhibition of bacteria was investigated by MIC assay [33]. For this threefold dilution of our samples was done.

$$
\text { Final concentration }=\frac{\text { Initial concentration }}{\text { Dilution factor }}
$$

Where,

$$
\text { Dilution factor }=\frac{\text { Total volume of reaction mixture }}{\text { Volume of sample taken }}
$$

The highest concentration comes out to be;

$$
\begin{gathered}
\text { Dilution factor }=\frac{200}{5}=40 \\
\text { Final concentration }=\frac{4000}{40} \frac{\mu \mathrm{g}}{\mathrm{ml}}=100 \frac{\mu \mathrm{g}}{\mathrm{ml}}
\end{gathered}
$$

So, four different concentrations of every sample were tested against all bacterial strains i.e. 100, 33.3, 11.1 and $3.7 \mu \mathrm{g} . \mathrm{mL}^{-1}$. After $24 \mathrm{~h}$ incubation the turbidity levels were checked [34].

\subsubsection{Antibacterial kinetics}

The optical density $\left(\mathrm{OD}_{630}\right)$ of all bacterial strains was determined to detect the growth with $2 \mathrm{~h}$ interval up to $6 \mathrm{~h}$ and then at 20, 22 and finally at $24 \mathrm{~h}$. It was done at $630 \mathrm{~nm}$ via microplate absorbance reader ELx800. Duplicate experiments were performed [35].

Growth Inhibition Percentage $\left.=\left(1-\frac{\text { oD630sample }}{\text { D630control }}\right) \times 100\right)$

\section{Results and Discussion}

\subsection{Nanomaterial Characterization}

Diffraction patterns of $\mathrm{ZnO} \mathrm{NP}$ are shown in Fig. 1(a) which shows lattice peaks at $31.77^{\circ}, 34.40^{\circ}, 36.22^{\circ}, 47.61^{\circ}, 56.58^{\circ}, 62.73^{\circ}, 67.93^{\circ}$, $69.08^{\circ}$, corresponding to $100,002,101,102,110,103,112,201$ crystal planes, respectively confirming the hexagonal wurtzite structure (JCPDS. 361451) [36]. These ZnO nanoparticles are prominently grown in (101) direction. It was noticed the synthesized sample is well crystalline and single phase with the absence of amorphous part. The lattice parameter $\mathrm{a}=\mathrm{b}=0.3222 \mathrm{~nm}$ and $\mathrm{c}=0.5216 \mathrm{~nm}$ are calculated and close to earlier reports. Fig. 1(b) shows the well crystalline diffracted XRD patterns at $2 \theta$ of values $32.12^{\circ}, 38.17^{\circ}, 44.31^{\circ}, 46.14^{\circ}$ and $64.44^{\circ}$ that could be attributed
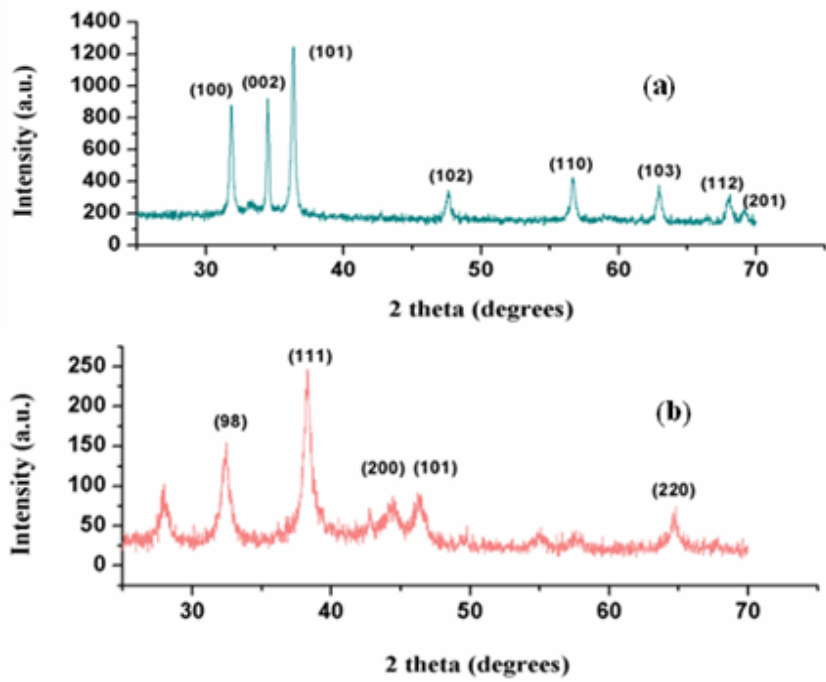

Fig. 1. XRD spectra (a) $\mathrm{ZnO}$ and (b) Ag nanoparticles.

to the 98, 111, 200, 101 and 220 planes, respectively. The XRD peaks indicating that structure of synthesized Ag NPs (JCPDS file no. 89-3722), hence it is clear that Ag NP synthesized from Ficus palmata leaf extract were essentially crystalline. The calculated lattice parameters for these Ag NP are $\mathrm{a}=\mathrm{b}=\mathrm{c} 0.4048 \mathrm{~nm}$ and close to previous reports [14].

The microstructure and morphology of the synthesized nanomaterials was obtained from SEM measurements. Fig. 2(a), (b) and (c) shows SEM images Ag NP. Apart from the characteristic bright appearance compered to $\mathrm{ZnO} \mathrm{NP}$, the Ag NP have a spherical appearance with particle size 50 to $67 \mathrm{~nm}$. Fig. 2 (d), (e) and (f) shows that the $\mathrm{ZnO}$ NP have flake like structure with average particle diameter of 45-60 $\mathrm{nm}$.

The elemental composition of the synthesized nanomaterials and elemental map (inset) could be elaborated by the representative SEM images coupled with the energy dispersive X-ray spectrum for both nanoparticles (Fig. 3 (a) for ZnO NP and (b) for Ag NP).

\subsection{Antibacterial Activity of Nanomaterials}

The antimicrobial activities against different pathogens like E. coli, K. pneumoniae, $P$. aeruginosa, S. aureus, B. subtilis, resistant $E$. coli, resistant $P$. aeruginosa and resistant $S$. haemolyticus were evaluated by determining MIC, kinetics growth curve analysis and growth inhibition percentages. For these studies, two broad spectrum antibiotics i.e., cefixime and roxithromycin were used as a control group.

\subsubsection{Minimum inhibitory concentration (MIC) and kinetics growth curve}

The least amount of dose that is needed to exhibit the bacteriostatic effect is said to be MIC of that sample. Micro-dilution technique was used to determine the MIC of analyzed nanomaterial samples [36]. For Gram positive strains, roxithromycin was tested as control whereas cefixime antibiotic for Gram negative and resistant strains. The activity was checked at four different concentrations which were 100, 33.3, 11.1 and $3.7 \mu \mathrm{g} . \mathrm{mL}^{-1}$. It was observed that 4 out 

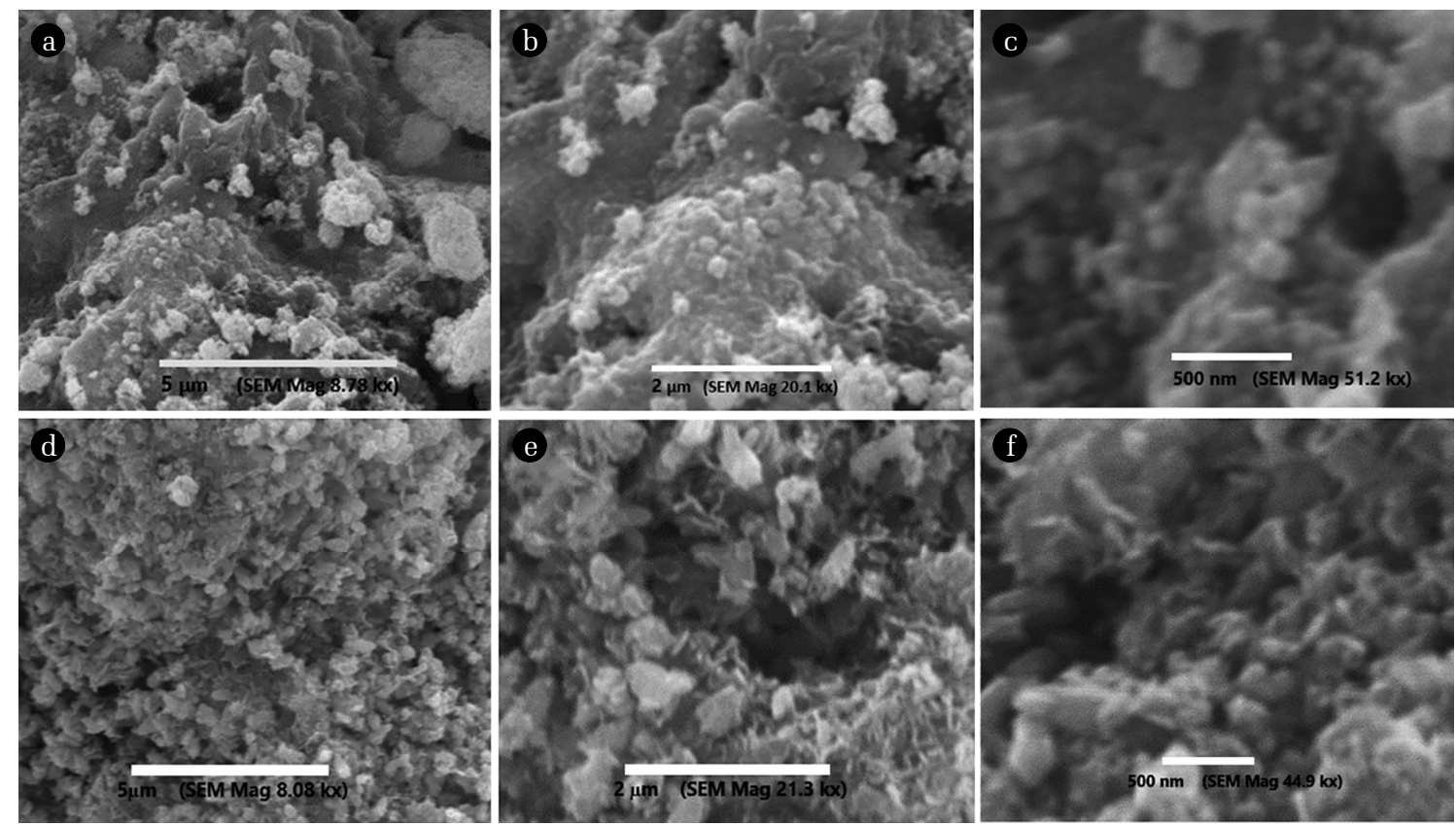

Fig. 2. SEM images (a), (b), (c) silver and (d), (e), (f) zinc oxide nanoparticles.
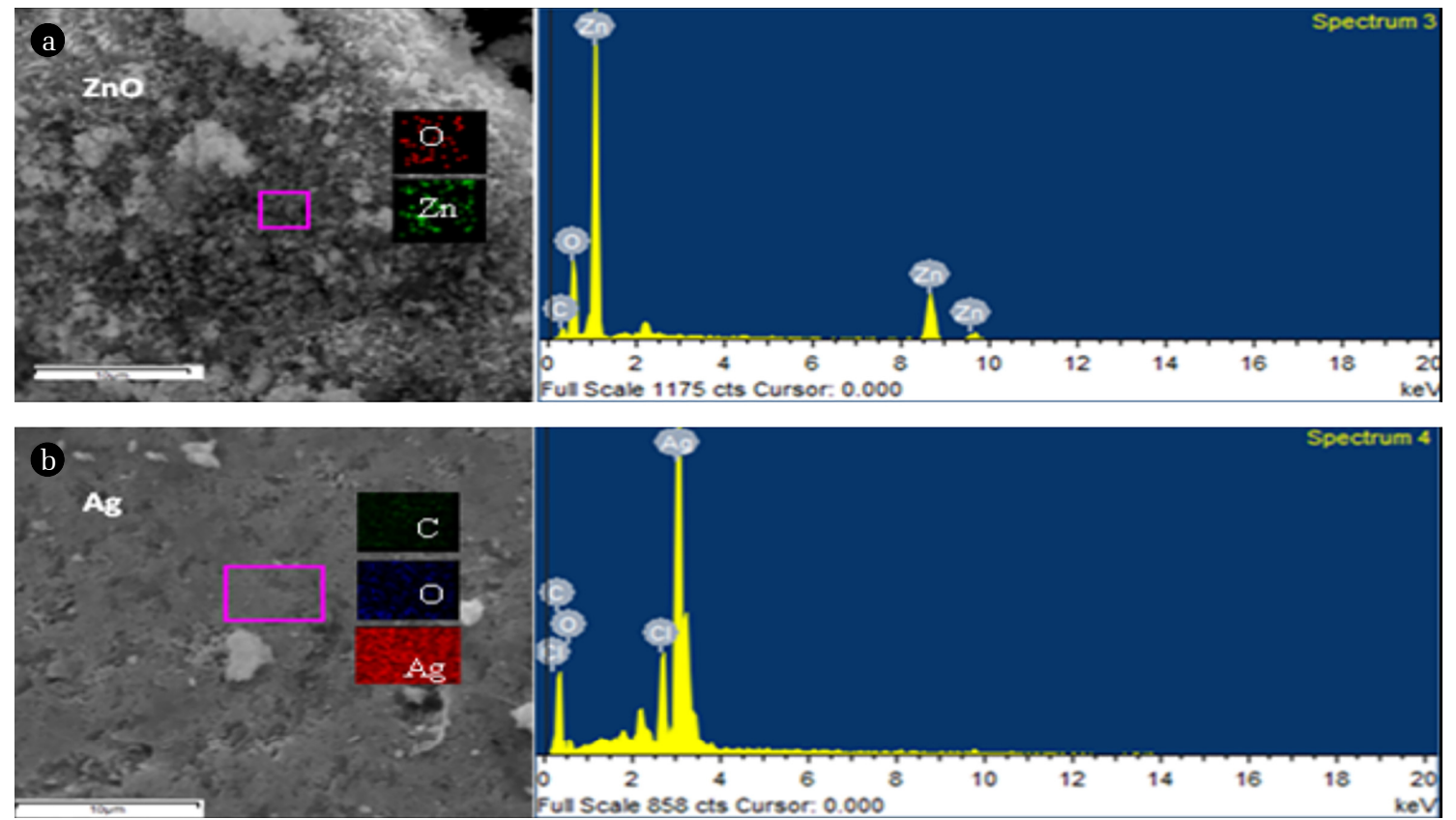

Fig. 3. SEM image with elemental map (inset) and corresponding EDS of (a) zinc oxide and (b) silver nanoparticles .

of 8 bacterial strains were sensitive to the antibiotics tested. The dose of $33.3 \mu \mathrm{g} \cdot \mathrm{mL}^{-1}$ of cefixime was sufficient for growth inhibition of $P$. aeruginosa and resistant $E$. coli. At the same time a larger dose $\left(100 \mu \mathrm{g} \cdot \mathrm{mL}^{-1}\right)$ of cefixime was required to inhibit $K$ pneumoniae. Significant bacterial growth was observed at the initial time, however after $20^{\text {th }} \mathrm{h}$ a decrease in growth was observed which can be seen in Fig. 4(a). Roxithromycin was found to be ineffective against both bacterial strains (B. subtilis and $S$. aureus) as shown in Fig. 4(b). All the nanoparticles showed greater activity than the positive control used for this experiment.

\subsubsection{Antibacterial silver nanoparticles}

Silver nanoparticles have been reported as alternative antibacterial and antioxidant agents in recent studies [37-39]. Silver nanoparticles (Ag NP) synthesized in this research were also found to be quite effective against bacteria and inhibited growth at different 

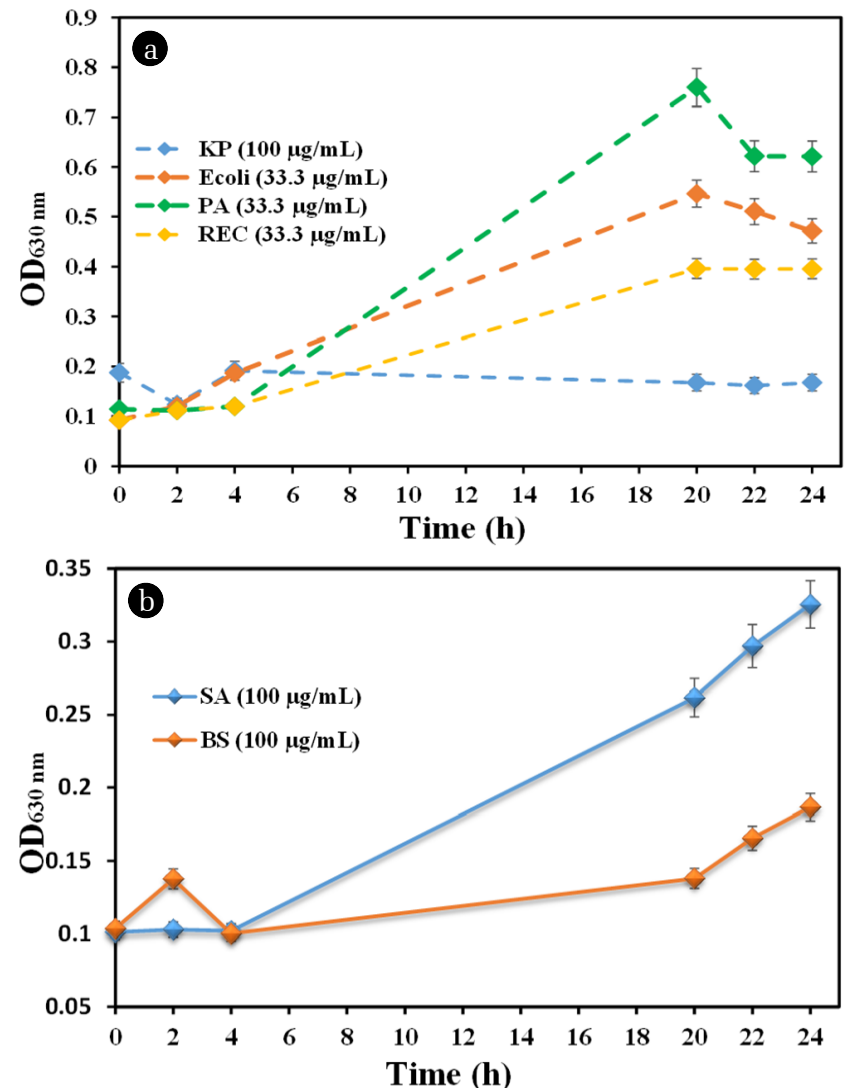

Fig. 4. MIC plots for different bacterial strains with (a) Cefixime and (b) Roxithromycin.

concentrations. But ineffective against only one bacterial strain $K$. pneumoniae. For $B$. subtilis, $P$. aeruginosa and resistant $E$. coli the MC was $100 \mu \mathrm{g} \cdot \mathrm{mL}^{-1}$. The growth of resistant $S$. haemolyticus was inhibited by using $33.3 \mu \mathrm{g} \cdot \mathrm{mL}^{-1} \mathrm{Ag} \mathrm{NP}$ while $11.1 \mu \mathrm{g} \cdot \mathrm{mL}^{-1}$ was required for $E$. coli and $S$. aureus. Ag NP MC against resistant P. aeruginosa was the lowest i.e. $3.7 \mu \mathrm{g} \cdot \mathrm{mL}^{-1}$ as shown in Fig. 5(a). A similar study was conducted by Agnihotri and co-workers in 2014, where significant antibacterial activity was observed by the Ag NP were synthesized via chemical route with MIC reported from 40 to $80 \mu \mathrm{g} \cdot \mathrm{ml}^{-1}$, respectively [40]. Similarly, Ag NP synthesized from the leaf extract of Alysicarpus monilifer showed greater activity as compared to the antibiotics erythromycin and amoxicillin used for the study [14]. Karunakaran and team synthesized silver and Magnesium nanoparticles from the Hydrangea paniculata flower extract. The synthesized nanoparticles were evaluated for bacterial growth inhibition compared with the antibiotic streptomycin used as a positive control. A greater zone of inhibition was seen for nanoparticles as compared to the positive control [41].

\subsubsection{Antibacterial zinc oxide nanoparticles}

Fig. 5(b) demonstrates that $\mathrm{ZnO} \mathrm{NP}$ were found active against 4 strains out of which only one was normal pathogenic strain while remaining three were resistant strains. Its activity was significantly potent against resistant $E$. coli as $3.7 \mu \mathrm{g} \cdot \mathrm{mL}^{-1}$ concentration showed inhibition effect, whereas, for Resistant $S$. haemolyticus
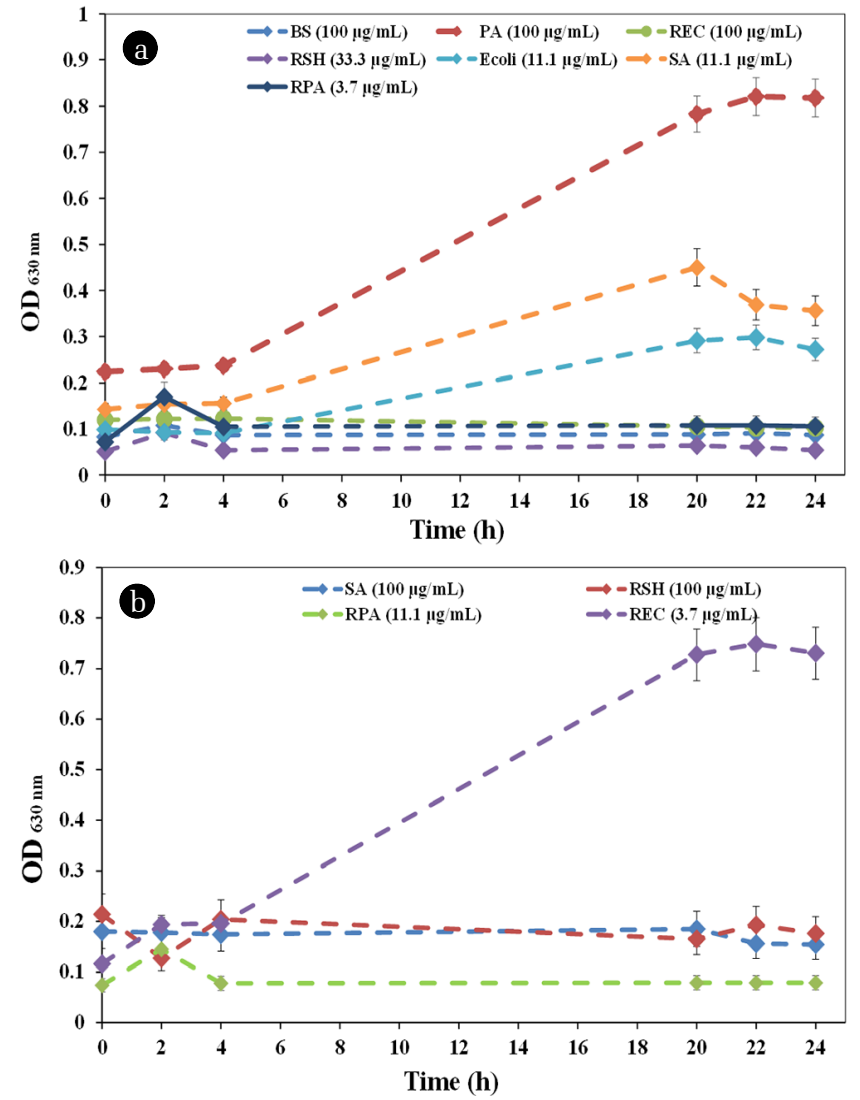

Fig. 5. Bacterial growth inhibition by green synthesized (a) Ag and (b) $\mathrm{ZnO}$ nanoparticles.

Table 1. Antibacterial Activities of $\mathrm{ZnO}$ and Ag Nanoparticles vs Antibiotic Controls

\begin{tabular}{lcccc}
\hline \multirow{2}{*}{$\begin{array}{l}\text { Bacterial } \\
\text { Strain }\end{array}$} & \multicolumn{4}{c}{ Control Species MIC $\left(\mu \mathrm{g.mL} \mathbf{H}^{-1}\right)$} \\
\cline { 2 - 5 }$E C$ & ZnO NP & Ag NP & Cefixime & Roxithromycin \\
\hline$B S$ & - & 11.1 & 33.3 & - \\
$K P$ & - & 100 & - & - \\
$P A$ & - & - & 100 & - \\
$S A$ & - & 100 & 33.3 & - \\
$\mathrm{REC}$ & 100 & 11.1 & - & - \\
$R S H$ & 3.7 & 100 & 33.3 & - \\
$R P A$ & 100 & 33.3 & - & - \\
\hline
\end{tabular}

and $S$. aureus $100 \mu \mathrm{g} \cdot \mathrm{mL}^{-1}$ concentration was needed to inhibit the bacterial growth. An inhibition effect was observed at 11.1 $\mu$ g. $\mathrm{mL}^{-1}$ concentration against Resistant $P$. aeruginosa as shown in Fig. 5(b). A similar study conducted in 2015 by Elumalai and Velmurugan showed significantly different results. The ZnO NPs prepared from Azadirachta indica (L.) was active for B. subtilis and $E$. coli where a dose of $6.25 \mu \mathrm{g} \cdot \mathrm{mL}^{-1}$ was sufficient for bacterial inhibition. While P. aeruginosa, Proteus mirabilis and E. coli showed growth inhibited at $25 \mu \mathrm{g} \cdot \mathrm{mL}^{-1}$ [42]. ZnO NP synthesized from 
Hibiscus rosa-sinensis leaf extract has been reported to show good antibacterial activity against pathogens. It showed better activity against $P$. aeruginosa whereas least activity was observed against K. pneumoniae [43]. An increase in antibacterial effect of nanoparticle is reported to be related to the miniscule particle size. The antibacterial activity of $\mathrm{ZnO} \mathrm{NP}$ was also found to be inversely related to its particle size [44]. The MIC of nanoparticles against different bacterial strains is summarized in Table 1 .

\subsubsection{Percentage growth inhibition}

The percentage growth inhibition is defined as:

$$
G I(\%)=\left(1-\frac{\text { oD630sample }}{\text { oD630control }}\right) \times 100
$$

Fig. 6(a) and (b) show the antibacterial activities at specific concentrations of $\mathrm{ZnO} \mathrm{NP}$ and Ag NP, respectively, against different pathogenic strains. As shown in Fig. 6(a), the ZnO NP were found to be active against resistant $S$. haemolyticus, resistant $P$. aeruginosa and $K$. pneumoniae. With time an increase in growth inhibition was observed. After $20^{\text {th }} \mathrm{h}$ the maximum inhibition was observed. $\mathrm{ZnO} \mathrm{NP}$ showed significant growth inhibition of resistant $S$. haemolyrticus and resistant $P$ aeruginosa. But even at $100 \mu \mathrm{g} \cdot \mathrm{mL}^{-1}$ the percent growth inhibition was low against $S$. aureus. Maximum growth inhibition was observed against resistant $S$. haemolyticus. For resistant $P$ aeruginosa $11.1 \mu \mathrm{g} \cdot \mathrm{mL}^{-1}$ concentration worked out quite well.
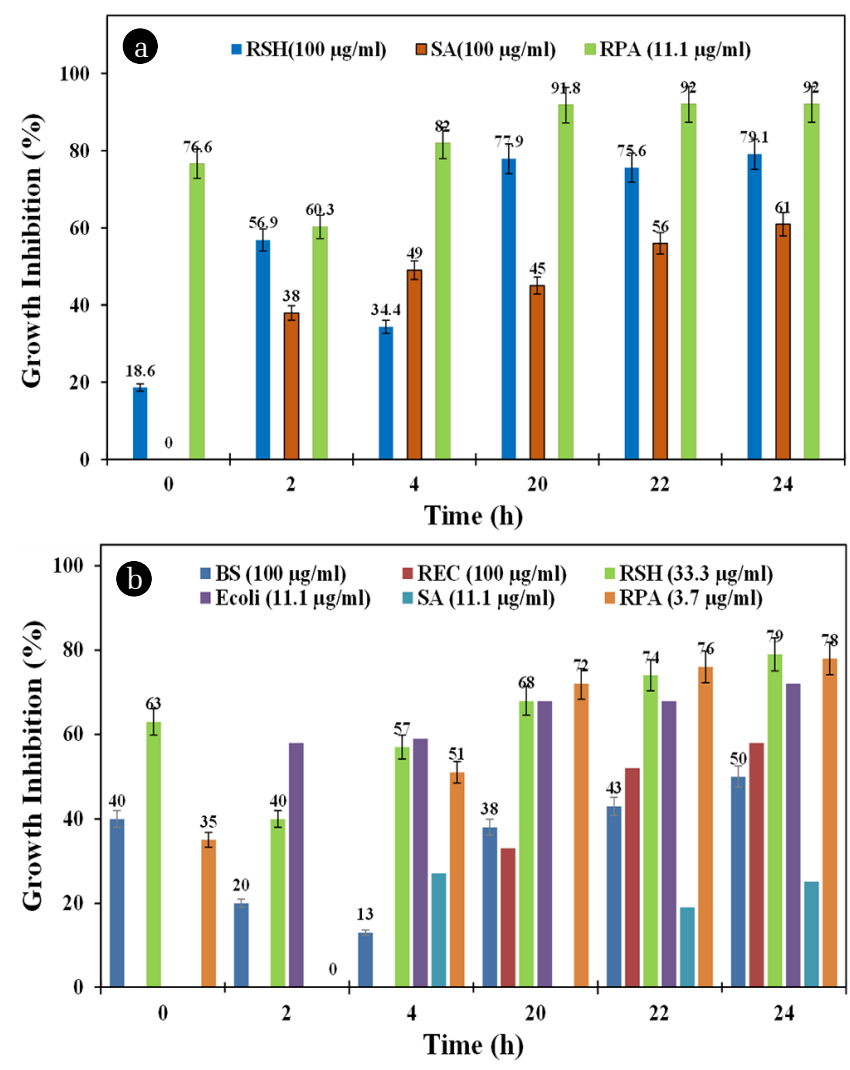

Fig. 6. Growth inhibition of bacterial strains by (a) $\mathrm{ZnO}$ and (b) $\mathrm{Ag}$ nanoparticles.
Silver nanoparticles are well known for the antibacterial effects, therefore, used widely in medical field as well. The Ag NP were potent against bacteria and exhibited antibacterial activity enhancement with time. Fig. 6 shows that growth of most of the strains was inhibited after $20^{\text {th }} \mathrm{h}$ of incubation and the percentages were highest at $24^{\text {th }} \mathrm{h}$. The inhibition percentage, however, was not promising for S aureus. As apparent from the Fig. 6(a) and (b), the inhibition percentages of nanoparticles are time dependent. Moghayedi and co-workers reported the mechanism of nanoparticles action over bacteria. It was reported that when treated with nanoparticles bacterial shape initially changes because of the damage caused to their membranes. Afterwards they became inactive and finally die after the leakage of the cytoplasm. Electrostatic attractions between the bacterial cell membrane and the nanoparticles were found to be the reason behind bacterial death [35]. The nanoparticle's small size and larger surface area can be the reasons behind such low MICs. It is reported that nanoparticles get attach to the cell membranes of bacteria thus disturbing bacterial cellular functions and permeability [44]. Jemal and co-workers reported that positive charge on nanoparticle ions is responsible for higher antimicrobial activity of silver NPs as it gets attached with the negative charge on bacterial membrane through electrostatic forces [9].

\section{Conclusion}

A rapid, environmentally benign and green route for synthesizing nano-sized zinc oxide and silver is reported using Ficus palmata Forssk leaf extracts. Efficient antibacterial activity of the synthesized nanoparticles was observed against drug resistant and responsive pathogenic bacterial strains. Silver NPs showed great potential against $S$. aureus, B. subtilis, E. coli, resistant E. coli, resistant $P$. aeruginosa and resistant $S$. haemolyticus at MIC concentrations as low as $3.7 \mu \mathrm{g} \cdot \mathrm{mL}^{-1}$. ZnO NPs also exhibited efficient antibacterial activity for $S$. aureus and resistant $P$. aeruginosa even at $11.1 \mu \mathrm{g} \cdot \mathrm{mL}^{-1}$. The antibacterial activity of synthesized nanomaterials was dose and time dependent. Green synthesized nanoparticles were found to be more effective compared with the antibiotic controls, cefixime and roxithromycin. The reported synthesis route is not only safe, eco- friendly but also provides an alternative route to conventional chemical synthesis of nanomaterials and further can be explored instead of conventional antibiotics.

\section{Acknowledgment}

The research was funded by Quaid-i-Azam University through University Research Fund 2017-18.

\section{Author Contributions}

S.S. (M.Phil. student) performed the experiments and wrote the draft. J.R. (Assistant Professor) designed the experiments, analysed data, and wrote the manuscript. I.U.H. (Assistant Professor) de- 
signed the antibacterial studies and revised the manuscript. N.I. (Associate Professor) and S.U.I. (Associate Professor) performed material characterizations.

\section{References}

1. Matamoros V, Rodríguez Y, Albaigés J. A comparative assessment of intensive and extensive wastewater treatment technologies for removing emerging contaminants in small communities. Water Res. 2016;88:777-785.

2. Al-Jassim N, Ansari MI, Harb M, Hong PY. Removal of bacterial contaminants and antibiotic resistance genes by conventional wastewater treatment processes in Saudi Arabia: is the treated wastewater safe to reuse for agricultural irrigation? Water Res. 2015;73:277-290.

3. Ashfaq M, Khan KN, Rehman MS, et al. Ecological risk assessment of pharmaceuticals in the receiving environment of pharmaceutical wastewater in Pakistan. Ecotoxicol. Environ. Saf. 2017;136:31-39.

4. Pugazhendhi A, Michael D, Prakash D, et al. Antibiogram and plasmid profiling of beta-lactamase producing multi drug resistant Staphylococcus aureus isolated from poultry litter. $J$. King Saud Univ. Sci. 2020;32:2723-2727.

5. Saravanan M, Niguse S, Abdulkader M, et al. Review on emergence of drug-resistant tuberculosis (MDR \& XDR-TB) and its molecular diagnosis in Ethiopia. Microb. Pathogenesis. 2018;117:237-242.

6. Shanmuganathan R, Ali DM, Prabakar D, et al. An enhancement of antimicrobial efficacy of biogenic and ceftriaxone-conjugated silver nanoparticles: green approach. Environ. Sci. Pollut. $R$ 2018;25:10362-10370.

7. Sisubalan N, Ramkumar VS, Pugazhendhi A, et al. ROS-mediated cytotoxic activity of $\mathrm{ZnO}$ and $\mathrm{CeO}_{2}$ nanoparticles synthesized using the Rubia cordifolia L. leaf extract on MG-63 human osteosarcoma cell lines. Environ. Sci. Pollut. R. 2018;25:1048210492.

8. Jemal K, Sandeep BV, Pola S. Synthesis, characterization, and evaluation of the antibacterial activity of Allophylus serratus leaf and leaf derived callus extracts mediated silver nanoparticles. J. Nanomater. 2017;2017:4213275.

9. Ahmed S, Ahmad M, Swami BL, Ikram S. A review on plants extract mediated synthesis of silver nanoparticles for antimicrobial applications: a green expertise. J. Adv. Res. 2016;7:17-28.

10. Alsohaimi IH, Nassar AM, Elnasr TA, Amar CB. A novel composite silver nanoparticles loaded calcium oxide stemming from egg shell recycling: A potent photocatalytic and antibacterial activities. J. Clean. Prod. 2020;248:119274.

11. Dizaj SM, Lotfipour F, Barzegar-Jalali M, Zarrintan MH, Adibkia K. Antimicrobial activity of the metals and metal oxide nanoparticles. Mater. Sci. Eng. C. 2014;44:278-284.

12. Rezaie AB, Montazer M, Rad MM. Environmentally friendly low cost approach for nano copper oxide functionalization of cotton designed for antibacterial and photocatalytic applications. J. Clean. Prod. 2018;204:425-436.

13. Kasithevar M, Saravanan M, Prakash P, et al. Green synthesis of silver nanoparticles using Alysicarpus monilifer leaf extract and its antibacterial activity against MRSA and CoNS isolates in HIV patients. J. Interdiscip. Nanomed. 2017;2:131-41.

14. Raza ZA, Rehman A, Mohsin M, et al. Development of antibacterial cellulosic fabric via clean impregnation of silver nanoparticles. J. Clean. Prod. 2015;101:377-386.

15. Mirzaei H, Darroudi M. Zinc oxide nanoparticles: Biological synthesis and biomedical applications. Ceram. Int. 2017;43: 907-914.

16. Ottoni CA, Simões MF, Fernandes S, et al. Screening of filamentous fungi for antimicrobial silver nanoparticles synthesis. AMB Express. 2017;7:1-10.

17. Dinesh D, Murugan K, Madhiyazhagan P, et al. Mosquitocidal and antibacterial activity of green-synthesized silver nanoparticles from Aloe vera extracts: towards an effective tool against the malaria vector Anopheles stephensi?. Parasitol. Res. 2015;114:1519-1529.

18. Singh PP, Bhakat C. Green synthesis of gold nanoparticles and silver nanoparticles from leaves and bark of ficus carica for nanotechnological applications. Int. J. Sci. Res. 2012;2:1-2.

19. Aminabee S, Rao AL, Sowmya K, et al. Evaluation of Analgesic Activity of Ficus Palmata. Iran. J. Pharm. Sci. 2019;15:47-60.

20. Basavegowda N, Idhayadhulla A, Lee YR. Preparation of Au and Ag nanoparticles using Artemisia annua and their in vitro antibacterial and tyrosinase inhibitory activities. Mater. Sci. Eng. C. 2014;43:58-64.

21. Jacob JM, John MS, Jacob A, et al. Bactericidal coating of paper towels via sustainable biosynthesis of silver nanoparticles using Ocimum sanctum leaf extract. Mater. Res. Express. 2019;6:4

22. Marulasiddeshwara MB, Dakshayani SS, Kumar MNS, Chethana R, Kumar PR, Devaraja S. Facile-one pot-green synthesis, antibacterial, antifungal, antioxidant and antiplatelet activities of lignin capped silver nanoparticles: A promising therapeutic agent. Mater. Sci. Eng. C.2017;81:182-190.

23. Marimuthua S, Antonisamy AJ, Malayandi S, et al. Silver nanoparticles in dye effluent treatment: A review on synthesis, treatment methods, mechanisms, photocatalytic degradation, toxic effects and mitigation of toxicity. J. Photoch. Photobio. B. 2020;205:111823.

24. Park S, Choi J. Geno- and Ecotoxicity Evaluation of Silver Nanoparticles in Freshwater Crustacean Daphnia magna. Environ. Eng. Res. 2010;15:23-27.

25. Samuel MS, Jose S, Selvarajan E, Mathimani T, Pugazhendhi A. Biosynthesized silver nanoparticles using Bacillus amyloliquefaciens; Application for cytotoxicity effect on A549 cell line and photocatalytic degradation of p-nitrophenol. J. Photoch. Photobio. B. 2020;202:111642.

26. You C, Han C, Wang X, et al. The progress of silver nanoparticles in the antibacterial mechanism, clinical application and cytotoxicity. Mol. Biol. Rep. 2012;39:9193-9201.

27. Brindhadevi K, Samuel MS, Verma TN, et al. Zinc oxide nanoparticles (ZnONPs) -induced antioxidants and photocatalytic degradation activity from hybrid grape pulp extract (HGPE). Biocatal. Agric. Biotechnol. 2020;28:101730.

28. Chandra H, Patel D, Kumari P, Jangwan JS, Yadav S. Phyto-mediated synthesis of zinc oxide nanoparticles of Berberis aristata: Characterization, antioxidant activity and antibacterial activity 
with special reference to urinary tract pathogens. Mater. Sci. Eng. C. 2019;102,212-220.

29. Karuppaiya P, Satheeshkumar E, Tsay HS. Biogenic synthesis of silver nanoparticles using rhizome extract of Dysosma pleiantha and its antiproliferative effect against breast and human gastric cancer cells. Mol. Biol. Rep. 2019;46:4725-4734.

30. Varadavenkatesan T, Lyubchik E, Pai S, Pugazhendhi A, Vinayagam R, Selvaraj R. Photocatalytic degradation of Rhodamine B by zinc oxide nanoparticles synthesized using the leaf extract of Cyanometra ramiflora. J. Photoch. Photobio. B. 2019;199:11162.

31. Vinayagama R, Selvaraj R, Arivalagan P, Varadavenkatesan T. Synthesis, characterization and photocatalytic dye degradation capability of Calliandra haematocephala-mediated zinc oxide nanoflowers. J. Photoch. Photobio. B. 2020;203:111760.

32. Rautray S, Panikar S, Amutha T, Rajananthini AU. Anticancer activity of Adiantum capillus veneris and Pteris quadriureta L. in human breast cancer cell lines. Mol. Biol. Rep. 2018;45:1897-1911.

33. Vicas CS, Keerthiraj N, Byrappa N, Byrappa K. Hydrothermally synthesized $\mathrm{Al}$-doped $\mathrm{BiVO}_{4}$ as a potential antibacterial agent against methicillin-resistant Staphylococcus aureus. Environ. Eng. Res. 2019;24:566-571.

34. Zahra SS, Ahmed M, Qasim M, et al. Polarity based characterization of biologically active extracts of Ajuga bracteosa Wall. ex Benth. and RP-HPLC analysis. BMC. Complem. Altern. M. 2017;17:1-6.

35. Moghayedi M, Goharshadi EK. Ghazvini K, et al. Kinetics and mechanism of antibacterial activity and cytotoxicity of Ag-RGO nanocomposite. Colloid. Surface. B. 2017;159:366-374.

36. Bala N, Saha S, Chakraborty M, et al. Green synthesis of zinc oxide nanoparticles using Hibiscus subdariffa leaf extract: effect of temperature on synthesis, anti-bacterial activity and anti-diabetic activity. RSC Adv. 2015;5:4993-5003.
37. Kup FO, Çoşkunçay S, Duman F. Biosynthesis of silver nanoparticles using leaf extract of Aesculus hippocastanum (horse chestnut): Evaluation of their antibacterial, antioxidant and drug release system activities. Mater. Sci. Eng. C. 2020;107: 110207.

38. Rafique M, Sadaf I, Tahir MB, et al. Novel and facile synthesis of silver nanoparticles using Albizia procera leaf extract for dye degradation and antibacterial applications. Mater. Sci. Eng. C. 2019;99:1313-1324.

39. Yousaf H, Mehmood A, Ahmad KS, Raffi M. Green synthesis of silver nanoparticles and their applications as an alternative antibacterial and antioxidant agents. Mater. Sci. Eng. C. 2020;112:110901.

40. Agnihotri S, Mukherji S, Mukherji S. Size-controlled silver nanoparticles synthesized over the range 5-100 nm using the same protocol and their antibacterial efficacy. RSC Adv. 2014;4:3974-3983.

41. Karunakaran G, Jagathambal M, Venkatesh M, et al. Hydrangea paniculata flower extract-mediated green synthesis of MgNPs and AgNPs for health care applications. Powder. Technol. 2017;305:488-494.

42. Elumalai K, Velmurugan S. Green synthesis, characterization and antimicrobial activities of zinc oxide nanoparticles from the leaf extract of Azadirachta indica (L.). Appl. Surf. Sci. 2015;345:329-336.

43. Shaker MA, Shaaban MI. Synthesis of silver nanoparticles with antimicrobial and anti-adherence activities against multidrug-resistant isolates from Acinetobacter baumannii. J. Taibah Univ. Medical Sci. 2017;12:291-297.

44. Divya MJ, Sowmia C, Joona K, Dhanya KP. Synthesis of zinc oxide nanoparticle from Hibiscus rosa-sinensis leaf extract and investigation of its antimicrobial activity. Res. J. Pharm. Biol. Chem. 2013;4:1137-1142. 